\title{
Dead-end and crossflow ultrafiltration process modelling: Application on chemical mechanical polishing wastewaters
}

\author{
Kelly Ohanessian, Mathias Monnot, Philippe Moulin, Jean-Henry Ferrasse, \\ Cristian Barca, Audrey Soric, Olivier Boutin*
}

Aix-Marseille Univ., CNRS, Centrale Marseille, M2P2 UMR 7340, 13451 Marseille, France

Keywords:

Dynamic modelling

Ultrafiltration

Nanoparticles

Wastewater treatment

\begin{abstract}
A B S T R A C T
Dynamic simulation of ultrafiltration process is applied to the treatment of chemical mechanical polishing wastewater from microelectronic industry. The ultrafiltration of nanoparticles (NPs) contained in chemical mechanical polishing wastewater is modelled by using different mathematical equations, which are derived from the literature and optimized to the effluent and filtration modes (dead-end or crossflow). A series of ultrafiltration experiments at laboratory scale are carried out by using chemical mechanical polishing wastewater to optimize and validate the models. Complete dead-end and crossflow ultrafiltration models are developed to simulate the treatment performances of chemical mechanical polishing wastewater under dynamic full-scale and different operating conditions, thus including filtration and washing steps. Simulations show that the dead-end mode is not suitable for chemical mechanical polishing wastewater concentration higher than $100 \mathrm{mgNPs} \mathrm{L}^{-1}$ due to the too fast fouling time and to the high frequency of washing step. The high concentration of chemical mechanical polishing P wastewater $\left(2600 \mathrm{mgNPs} \mathrm{L}^{-1}\right.$ ) forces industries to use crossflow ultrafiltration to have a profitable process by controlling parameters such as the filtration/backwashing number of cycles, the needed filtering surface and the filtration flux.
\end{abstract}

\section{Introduction}

The development of membrane-based processes such as microfiltration (MF), ultrafiltration (UF) and reverse osmosis (RO) has received increasing attention from the scientific community (Huang et al., 2011; Lo and Lo, 2004; Springer et al., 2013; Trzaskus et al., 2017). The diversity of membrane technologies allows to eliminate many compounds from aqueous suspensions, both to produce drinking water or to treat wastewater. Membrane processes can effectively remove suspended solids and fractions of dissolved solids, including microorganisms, colloids, organic matters, and inorganic

Abbreviations: CW, chemical wash; NPs, nanoparticles.

* Corresponding author.

E-mail address: olivier.boutin@univ-amu.fr (O. Boutin). particles (Choi et al., 2005; Trzaskus et al., 2017). Among the different membrane technologies, UF appears to be one of the most appropriate techniques for the removal of nanoparticles (NPs) and colloidal particles, as indicated by several studies already published in the literature (Bacchin et al., 2002; Kim et al., 2006; Le Hir et al., 2018; Pansare et al., 2017; Srijaroonrat et al., 1999; Waite et al., 1999). Although the number of applications of membrane filtration is increasing, these systems have some major disadvantages. The decline of permeate flux due to the membrane fouling results in a decrease of performance. On the other hand, the membrane operation is interrupted by the repeated physical cleaning steps as well as by the chemical cleanings that restore the original membrane performance. Strong savings and a prominent level of productivity can be expected if control of these units is improved. Therefore, modelling the dynamics of membrane behaviour is very important. Currently, the membrane models available 


\begin{tabular}{|c|c|}
\hline \multicolumn{2}{|c|}{ Nomenclature } \\
\hline$a$ & Eq. (8) coefficient $(-)$ \\
\hline $\operatorname{As}\left(\theta_{\max }\right)$ & $\begin{array}{l}\text { correction function for the effect of neighbour- } \\
\text { ing particles in the cake layer based on Happel's } \\
\text { cell mode }(-)\end{array}$ \\
\hline$a_{p}$ & particle radius $(\mathrm{m})$ \\
\hline$b$ & Eq. (8) coefficient (-) \\
\hline$C_{0}$ & feed particle concentration $\left(\mathrm{kg} \mathrm{m}^{-3}\right)$ \\
\hline$D$ & diffusion coefficient $\left(\mathrm{m}^{2} \mathrm{~s}^{-1}\right)$ \\
\hline$d_{p}$ & particle diameter $(\mu \mathrm{m})$ \\
\hline$e$ & Eq. (9) coefficient (-) \\
\hline$f$ & Eq. (9) coefficient (-) \\
\hline$f_{c}$ & correction factor $\left(\mathrm{m}^{4} \mathrm{~s}^{-1} \mathrm{~kg}^{-1}\right)$ \\
\hline VCF & volume concentration factor (-) \\
\hline J & permeate flux $\left(\mathrm{ms}^{-1}\right)$ \\
\hline$J_{F}$ & average permeate flux $\left(\mathrm{m} \mathrm{s}^{-1}\right)$ \\
\hline$J_{0}$ & initial permeate flux $\left(\mathrm{m} \mathrm{s}^{-1}\right)$ \\
\hline$J_{C_{0}}$ & permeate flux for $\mathrm{VCF}=1\left(\mathrm{~m} \mathrm{~s}^{-1}\right)$ \\
\hline$k$ & mass transfer coefficient $(-)$ \\
\hline$k_{B}$ & Bolztmann constant $\left(\mathrm{JK}^{-1}\right)$ \\
\hline$L_{p_{0}}$ & $\begin{array}{l}\text { membrane } \\
\left(\mathrm{Lh}^{-1} \mathrm{~m}^{-2} \mathrm{bar}^{-1}\right)\end{array}$ \\
\hline$n$ & porosity (-) \\
\hline Nc & number of cycles $(-)$ \\
\hline Qp & permeate flowrate $\left(\mathrm{m}^{3} \mathrm{~s}^{-1}\right)$ \\
\hline$R_{m}$ & membrane resistance $\left(\mathrm{m}^{-1}\right)$ \\
\hline Sf & filtering surface $\left(\mathrm{m}^{2}\right)$ \\
\hline $\mathrm{T}$ & temperature $(\mathrm{K})$ \\
\hline t & filtration time (s) \\
\hline TMP & transmembrane pressure $(\mathrm{Pa})$ \\
\hline$u$ & tangential velocity $\left(\mathrm{m} \mathrm{s}^{-1}\right)$ \\
\hline$\theta$ & porosity dependent variable used in Eq. (4) (-) \\
\hline$\mu$ & dynamic viscosity of the suspension (Pa s) \\
\hline$\rho_{\mathrm{S}}$ & particle density $\left(\mathrm{kg} \mathrm{m}^{-3}\right)$ \\
\hline
\end{tabular}

in the literature are classified according to two categories: (i) the end use and (ii) the comprehension of the fouling phenomenon (Saltık et al., 2017). The first class includes different model structures, ranging from static models (or black box) in which the relationships between internal variables are built by linear regression (Pascual et al., 2013), medium lumped models (Guadix et al., 2004) and large-scale models considering the spatial dependence of membranes (Van der Sman and Vollebregt, 2013). The second class concerns the introduction of fouling in membrane models. Several authors investigated the characterization of the membrane fouling phenomenon with a gel layer formation and/or concentration polarization as well as cake formation and/or pore blocking (Bacchin et al., 2002; Chen et al., 1997; Elimelech and Bhattacharjee, 1998; Sioutopoulos and Karabelas, 2012). Other authors evaluate the overall performance of membrane processes as a function of operating parameters (Yee et al., 2009, 2008; Yorgun et al., 2008). Different types of dynamic membrane models are proposed in the literature: mathematical models in the form of data-driven models, lumped models, and distributed parameters models (Cheng and Yeh, 2008; Guadix et al., 2004; Marriott et al., 2001; Pascual et al., 2013). Data-driven models are well suited for accurately describing processes behaviour making use of historical plants data without having to rely on predetermined process parameters. Such models can easily describe complex and non-linear systems but their validity are limited (Saltık et al., 2017). Lumped models consist of a set of integral, differential and algebraic equations comprising integer and continuous variables. In these systems, the dependent variables of interest are a function of time alone. Such models are particularly appreciated because they use physical properties and quantitative parameters. Finally, in distributed systems, all dependent variables are functions of time and one or more spatial variables which make process modelling more complex. The last ones (lumped and distributed models) are often preferred because they could provide some important useful knowledges for membrane processes design. But in many cases, lumped models are more attractive: generally, in distributed models, many assumptions must be made which may reduce the reliability of the models. A simple lumped parameter approach using easily obtainable parameters could offer equally reliable solutions and reduce numerical efforts (Sanders and Hubble, 1991). The most important thing in model development is its ultimate usefulness. Indeed, the development of systemic models that integrate the filtration and washing steps under full scale dynamic conditions is crucial to improve the design and operation of the UF units. The UF model proposed in this study is a hybrid model based on combined lumped/data-driven models. Analytical equations (lumped system) allow to predict the permeate flux decline in function of filtration duration and various physical parameters. Furthermore, experimental data are used to confirm and/or improve the permeate flux decline model (data-driven system). On the other hand, data from the literature about cleaning steps are used to complete the UF model in order to evaluate the global performances and to design the UF units. This hybrid model seems to be more attractive than the use of only one modelling system. It allows to couple the advantages of lumped model with using physical membrane parameters and data-driven model using experimental data which finally gives a specific UF model adapted to industrial effluents.

The treatment of chemical mechanical polishing (CMP) wastewater is of high interest for industrials. Indeed, the rapid growth of nanotechnologies has led to an increasing production of effluents from the semiconductor and microelectronic industries (Baudry, 2014). Some researchers have been studying the treatment of different types of wastewaters produced by the microelectronic industries (Chou et al., 2009; de Luna et al., 2009; Ji et al., 2010; Ryu et al., 2008), and in particular the treatment of effluents loaded with NPs (Chin et al., 2006; Liu et al., 2016). In semiconductor industry, NPs are one of the major components of polishing liquids (slurries) that are used in the CMP step of the microchip manufacturing process. The slurries used in CMP process are acidic or basic abrasive solutions containing small silica beads $\left(\mathrm{SiO}_{2}\right)$ as NPs. The CMP process involves two major types of interactions between the slurries and the semiconductor surface: (i) a chemical interaction that transforms the chemical and mechanical properties of the surface of the semiconductor and (ii) a mechanical interaction due to the abrasive particles (silica beads) that are present in the slurries (Bernard, 2006). UF allows to concentrate macromolecular solutions and to remove particles with size ranging from 0.002 to $0.1 \mu \mathrm{m}$, including most of the silica colloids and NPs present in CMP wastewater (Tsai et al., 2007). It should be also noted that the reuse, recycling, or reclamation of the CMP wastewater is becoming an important issue because of the high amount of ultrapure water that is required by semiconductor industry (Testa et al., 2011, 2014). Therefore, UF may represent a suitable solution to: (i) remove slurry par- 
ticles, and to (ii) reuse the purified CMP wastewater after the UF treatment.

To the best of our knowledge, in the literature, there is no study on the dynamic simulation of UF process applied to the treatment of CMP wastewater. Consequently, this study aims to propose complete dead-end and crossflow UF models to specifically simulate and control the removal of NPs contained in CMP effluents from the microelectronic industry.

For that purpose, the effects of different NPs concentrations under different transmembrane pressures (TMPs) are first investigated by a series of experiments performed in dead-end and crossflow filtration modes with real and diluted CMP effluent in order to determine the most suitable filtration method. Then, experimental results are used to validate and improve a mathematical model that describes the evolution of flux decline as a function of the filtration time. Systemic models for the full UF processes, including filtration/backwash cycles and chemical washings (CWs), are developed based on experimental and literature data. Finally, the treatment efficiencies of CMP effluent under dynamic full-scale conditions are simulated.

\section{Material and methods}

\subsection{Experiments}

\subsubsection{CMP wastewater}

The real CMP wastewater used in this study was provided by Rockwood industry (Gréasque, France). The NPs contained in the CMP wastewater present an average size of $94.5 \mathrm{~nm}$ and a median size of $100.9 \mathrm{~nm}$ with NPs size ranging from 50.7 to $190.1 \mathrm{~nm}$. Size distributions are obtained with Zetasizer Nano S (Malvern, England). All measurements are performed at $20^{\circ} \mathrm{C}$. The NPs concentration of CMP wastewater was $2600 \mathrm{mgNPs} \mathrm{L}^{-1}$, based on the weight of solid residue after drying liquid samples at $105^{\circ} \mathrm{C}$ until constant weight. The real CMP wastewater was then diluted with ultrapure water $(>18.18 \mathrm{M} \Omega \mathrm{cm})$ to prepare solutions at six different NPs concentrations, $97,251,332,572,657$, and $2600 \mathrm{mgNPs} \mathrm{L}^{-1}$, this to investigate the effect of different NPs concentrations on duration and efficiency of the filtration step. Coarse and random dilutions between 100 and $2600 \mathrm{mg} \mathrm{L}^{-1}$ of NPs were done. Due to the dilution method, concentrations are measured a posteriori.

\subsubsection{Membranes}

The membranes used for the UF process are multi-channel (7 channels) organic hollow fibres (ALTEON ${ }^{\mathrm{TM}}$ I, SUEZ aquasource ${ }^{\circledR}$, France). They are made of hydrophilic polyethersulfone and present a cut-off of $200 \mathrm{kDa}$ for a nominal pore size of $20 \mathrm{~nm}$ according to manufacturer's data. The internal diameter of a channel is $0.9 \mathrm{~mm}$ and the outer diameter of a fibre is $4 \mathrm{~mm}$. These membranes allow internal-external filtration and have a permeability of $1060 \pm 60 \mathrm{~L} \mathrm{~h}^{-1} \mathrm{~m}^{-2}$ bar $^{-1}$ (average value \pm standard deviation).

\subsubsection{Ultrafiltration setup}

Ultrafiltration experiments are performed in three multichannel hollow fibres placed in an external shell (PVC) drilled in the centre allowing the permeate flow. Before the experiments, the membranes are flushed with ultrapure water under 1 bar of TMP to remove residues of the glycerine used for membrane preservation (Arénillas et al., 2017). After membrane flushing, the initial permeability of the membrane is determined by measuring the permeate flux under different TMPs. For each value of TMP, the permeate flux was measured three times. Two different filtration modes, dead-end and crossflow, were tested as described in the following sections, in order to establish the most suitable mode for CMP wastewater filtration.

2.1.3.1. Dead-end filtration. A series of dead-end UF experiments is performed to evaluate the effect of three different initial NPs concentrations obtained with dilution from the real CMP wastewater $\left(97,251\right.$ and $\left.657 \mathrm{mgNPs} \mathrm{L}^{-1}\right)$ on filtration duration and performance. All the experiments are carried out at 0.4 bar of TMP according to a vertical dead-end filtration mode, using the laboratory-scale experimental setup presented in Fig. 1A. For each experiment, the permeate flux is monitored during the filtration step. When doing dead-end filtration, all the feed is filtered through the membrane. Some solids and compounds, depending on the pore size of the membrane, remain behind the membranes while the water passes through them. Therefore, there is then a greater resistance to pass the membrane. When the pressure of the feed water is constant, the permeate flux decreases. After a while, the flow has decreased so much that the membrane needs to be cleaned. In dead-end filtration, the ends of the fibres are clogged and the retentate remains trapped inside of it. This mode of filtration allows to concentrate a solution very quickly but generates a strong fouling.

Crossflow filtration. Crossflow UF experiments are performed to evaluate the effect of three different initial NPs concentrations obtained with dilution from the real CMP wastewater $\left(332,572\right.$ and $2600 \mathrm{mgNPs} \mathrm{L}^{-1}$ ) on filtration duration and performance. All the experiments are performed at 0.3 bar of TMP according to a vertical crossflow filtration mode with retentate recirculation considering a tangential velocity of $0.5 \mathrm{~m} \mathrm{~s}^{-1}$. The laboratory-scale experimental setup presented in Fig. 1B is used. Indeed, in the TMP range considered, the velocity has a moderate influence (Ndiaye et al., 2004) and a relatively low velocity can limit the pressure losses and provide a more homogeneous filtration along the length of the fibre. A rather low velocity value is then set $\left(0.5 \mathrm{~m} \mathrm{~s}^{-1}\right)$, but not too low either, thus allowing to reduce fouling effect. For each experiment, the permeate flux is monitored during the filtration step. In crossflow filtration, the solution circulates along the fibres with a shear rate which limits the fouling phenomenon. The ends of the fibres are not clogged and the retentate can be harvested. One of the disadvantages of the tangential filtration is that it requires the use of an additional pump to maintain a recirculation of the retentate.

\subsection{Modelling}

\subsubsection{Filtration flux modelling}

The experimental results of permeate flux $(J)$ as a function of filtration time are modelled according to the model of Hong et al. (1997), which is developed for the filtration of colloidal silica suspensions. The model is based on a simplified particle mass balance for the early stages of crossflow filtration under constant TMP, before a steady state flux is reached. Hong et al. (1997) mentioned that tangential velocity has no influence on the permeate flux during the transient stage of crossflow filtration. They explained that all particles are transported to the membrane surface and, as the cake layer thickness approaches steady state, the permeate flux increases slightly with increasing shear rate. Generally, the fall of the permeate flux in the first seconds of filtration is assimilated to a dead- 

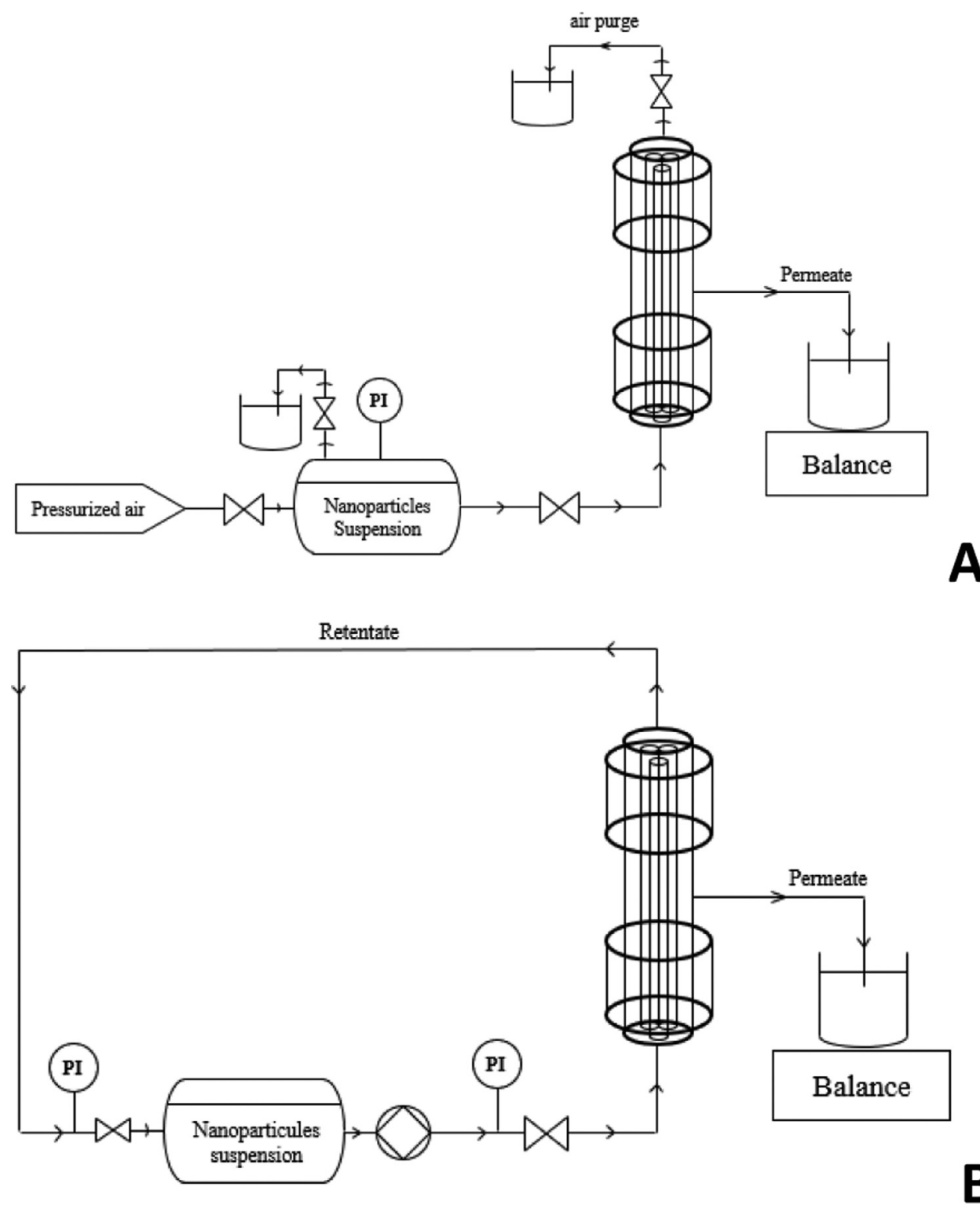

Fig. 1 - Setup for A. dead-end and B. crossflow ultrafiltration experiments.

end filtration. The model of Hong et al. (1997) derived from the application of particle transport and mass conservation equations, and it considers the formation of a polarization layer on the membrane surface. In order to simplify the equations, Hong et al. (1997) made several hypotheses as summarized in the following section, which are also valid in this study, and they finally proposed an equation representing the evolution of the permeate flux as a function of the filtration time (Eq. (1)), where $J_{0}$ is the initial permeate flux $\left(\mathrm{m} \mathrm{s}^{-1}\right), k_{\mathrm{B}}$ is the Boltzmann constant $\left(\mathrm{JK}^{-1}\right)$, T is the temperature $(\mathrm{K})$, $\mathrm{As}\left(\theta_{\max }\right)$ is a correction function for the effect of neighbouring particles in the cake layer based on Happel's cell model $(-), C_{0}$ is the feed particle concentration $\left(\mathrm{kg} \mathrm{m}^{-3}\right)$, TMP is the transmembrane pressure $(\mathrm{Pa}), a_{p}$ is the particle radius $(\mathrm{m}), \mathrm{D}$ is the diffusion coefficient of the particles $\left(\mathrm{m}^{2} \mathrm{~s}^{-1}\right), \mu$ is the dynamic viscosity of the solution (Pas), $R_{m}$ is the membrane resistance $\left(\mathrm{m}^{-1}\right), \rho_{\mathrm{s}}$ is the particle density $\left(\mathrm{kg} \mathrm{m}^{-3}\right)$, and $t$ is the time (s):

$J=J_{0}\left(1+\frac{3 k_{\mathrm{B}} \mathrm{TAs}\left(\theta_{\mathrm{max}}\right) C_{0} \mathrm{TMP}}{2 \pi a_{p}^{3} D\left(\mu R_{m}\right)^{2} \rho_{\mathrm{S}}}\right)$
The diffusion coefficient of the silica particles is determined by the Stokes-Einstein relation (Eq. (2)):

$$
D=\frac{k_{B} T}{6 \pi \mu a_{p}}
$$

The correction function $\operatorname{As}\left(\theta_{\max }\right)$ is related to the porosity of the filtration cake formed at the surface of the membrane, as already describes by Happel (1958) and Happel and Brenner (1965). In this study, $A s\left(\theta_{\max }\right)$ is determined by Eq. (3), where $\theta$ is a dimensionless variable that depends on the porosity $n$ of the cake, as shown by Eq. (4):

$$
\begin{aligned}
& \operatorname{As}\left(\theta_{\text {max }}\right)=\frac{1+(2 / 3) \theta^{5}}{1-(3 / 2) \theta+(3 / 2) \theta^{5}-\theta^{6}} \\
& \theta=(1-n)^{(1 / 3)}
\end{aligned}
$$

Hong et al. (1997) considered the porosity $n$ equal to 0.36 , which corresponds to the minimum theoretical porosity of a sphere stack. However, Lee and Clark (1998) have shown that the actual porosity depends on the size of spherical particles, and they proposed a relation between cake porosity $n$ and par- 
ticle size (Eq. (5)), where $d_{p}$ is the particle diameter $(\mu \mathrm{m})$, based on the Carmen-Kozeny equation:

$n=0.11 \times \frac{1}{\sqrt{d_{p}}}+0.053$

For crossflow configuration (Fig. 1B), the feed NPs concentration increases over time since only the retentate is recycled in the feed tank. Lee and Clark (1998) studied the effect of particle feed concentration on the permeate flux and they observed the cake resistance increases linearly with the feed concentration, while the specific cake resistance remains constant regardless of feed concentrations. This supports the idea that a high feed concentration only results in a thicker cake and the feed concentration does not affect the specific cake resistance. Moreover, the feed concentration would not influence the properties (i.e. porosity) of the cake layer. Furthermore, Lee and Clark (1998) studied the effect of TMP on the permeate flux and they showed in this case that both the cake resistance and specific cake resistance are linearly proportional to the TMP. They also determined the theoretical porosity values with each specific cake resistance values for different TMPs and they observed that the porosity tends to decrease with increasing TMP, indicating that a higher TMP results in a more compact cake layer. However, in this study, the TMP is a constant parameter and does not influence the cake compaction. Thereby, NPs concentration corresponds to the feed concentration $C_{0}$ and the cake porosity $n$ only depends on the NPs size.

From Eq. (1), it is then possible to visualize the evolution of the permeate flux as a function of the filtration time for dead-end filtration mode according to various physical operating parameters. This filtration model is also improved and adapted for crossflow filtration mode in this paper. The root mean squared error (RMSE) is used as objective evaluative criterion to evaluate the performance of the proposed filtration models, as RMSEs analysis is performed to minimize the difference between experimental and theoretical filtration fluxes for the two filtration modes to validate the equations.

\subsubsection{UF units modelling}

The aim of this paper is to propose a complete model of the UF process including filtration/backwash cycles between two CWs under conditions as close as possible to the reality. To reach thus purpose, data of backwashes (BWs) and CW mechanisms are discussed and finally determined from the literature to carry out the model.

BWs are used to regenerate the membrane by eliminating the reversible fouling. However, irreversible fouling appears as filtration progresses, and a CW is trigged when BWs are no longer effective (loss of $80 \%$ of the initial membrane permeability). According to the literature, the duration of UF BW in water treatment is between $30 \mathrm{~s}$ to $3 \mathrm{~min}$ (Berland and Juery, 2002). Vera et al. (2015) observed that cake redispersion became deficient as the BW duration is shorter (15 s) thus intensifying the pre-deposition process. Studies by Ye et al. (2011) showed that the fouling rate decreased by more than $50 \%$ while increasing BW duration from 10 to $30 \mathrm{~s}$, but no significant improvement is observed for further increases of BW duration. Akhondi et al. (2014) studied the influence of BW duration and they observed that fouling rate did not vary considerably with increasing the backwash duration from $30 \mathrm{~s}$ to $3 \mathrm{~min}$. However, the BW duration can influence the number of filtration cycles, as already observed by Akhondi et al.
(2014), who indicated that the net permeate volume increases to a maximum value with increasing the BW duration up to 2 min. Finally, Payant (2016) and Cordier et al. (2018) mentioned that UF membranes are frequently physically washed every 20-60 min with a BW duration of 1-2 min. It is also mentioned that after each filtration/backwash cycle the membrane does not recover $100 \%$ of its initial permeability, but rather 90-97\% (Payant, 2016; Remize et al., 2010), due to the irreversible fouling. Remize et al. (2010) showed $97 \%$ of membrane permeability recovery under 2 bar of TMP during 20-40 s of BW duration. Ye et al. (2011) observed that the cake thickness increased along with the consecutive filtration/backwashing cycles despite the cake resistance remained almost similar during the full filtration process, thus suggesting that there were no changes in the cake structure overtime. Moreover, the authors found that the values of the cake resistance increased as a function of number of BW cycles, thus indicating a decrease on BW efficiency. According to these literature data and the type of membrane used in this study, BWs are modelled considering an average of $97 \%$ of membrane permeability recovery after 1 min of BW given by Cordier et al. (2018) with a similar membrane. The number of filtration/backwash cycles is determined according to a minimum final permeability of membrane $L_{p_{f}}$ corresponding to $20 \%$ of the initial membrane permeability $L_{p_{0}}$. After each filtration/backwashing step, the new membrane permeability is determined as $97 \%$ of the initial membrane permeability of the previous cycle, this until reach $L_{p_{f}}$. BW is trigged after a fixed filtration time (20-60 min). The proposed model also includes the fact that CW is triggered when the permeability limit $L_{p_{f}}$ is reached. According to the literature, $2-3 \mathrm{~h}$ of $\mathrm{CW}$ is preconized (Diagne, 2014) and a duration of $3 \mathrm{~h}$ is considered for simulation.

For the dead-end filtration mode, an integration of the permeate flux over the filtration time for each filtration cycle allows to determine an average flux of permeate $\left(J_{F}\right)$ and the filtering surface (Sf) is calculated by Eq. (6), thus considering the total process duration (filtrations $+\mathrm{BWs}+\mathrm{CW}$ ) in order to propose a sizing including all the stages of the process. The term $\mathrm{Qp}$ in Eq. (6) represents the average fixed permeate flowrate corresponding to the feed flow (in this study $100 \mathrm{~m}^{3} \mathrm{~h}^{-1}$ ):

$J_{F}=\frac{Q p}{S f}$

For the crossflow mode, the volume concentration factor (VCF), defined as the ratio between the feed volume and the retentate volume, is determined according to Eq. (7) by using the modelled permeate flux $J$ described by Eq. (11), where $J_{C_{0}}$ is the permeate flux for VCF equal to 1 and $k$ is the mass transfer coefficient:

$J=J_{C_{0}}-k \ln (\mathrm{VCF})$

However, considering $97 \%$ of membrane permeability recovery after each $\mathrm{BW}$, the membrane permeability decreases at each cycle, thus leading to variations on the values of the parameters $J_{C_{0}}$ and $k$. As shown by Eqs. (8) and (9), correlations between each coefficient and the number of cycles Nc are determined for each suspension under fixed operating conditions (TMP, temperature, tangential velocity, and initial membrane permeability), with $a, b, c, e, f$ and $g$ the empirical coefficients calculated for the different conditions considered:

$J_{C_{0}}\left(N c, T M P, T, u, L_{p_{0}}\right)=a N c^{2}+b N c+c$ 


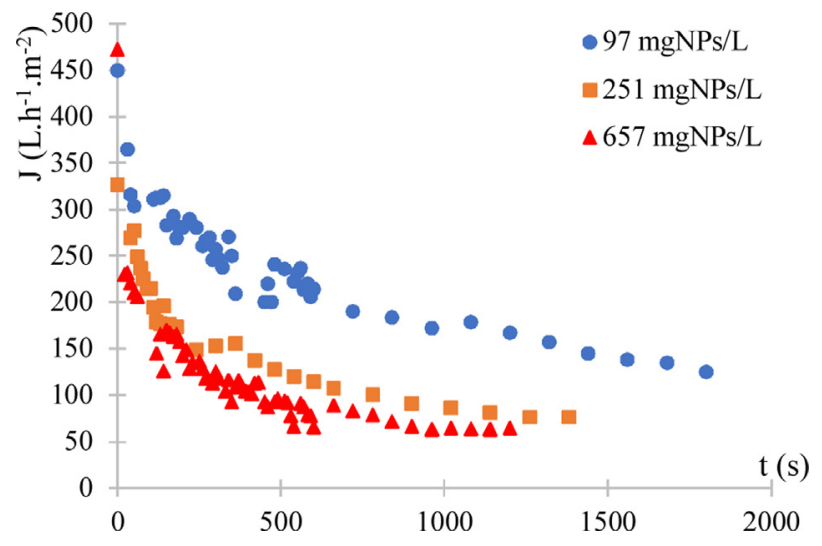

Fig. 2 - Experimental permeate flux as a function of filtration time for the different NPs concentrations [TMP $=0.4$ bar, dead-end filtration. $\left.\mathrm{T}=20^{\circ} \mathrm{C}\right]$.

$k\left(N c, T M P, T, u, L_{p_{0}}\right)=e N c^{2}+f N c+g$

Then, the retentate flowrates are determined according to the VCF considered for each cycle. Retentate concentrations and permeate flowrates are calculated for each cycle by mass balance with considering a zero concentration of NPs in the permeate. The filtering surface (Sf) is deduced considering the total process duration, an average permeate flowrate $(Q p)$ and an average permeate flux $\left(J_{F}\right)$ by using Eq. (6). Finally, the BW volume per $\mathrm{m}^{2}$ of membrane surface is estimated at about $10 \%$ of filtered volume (Cordier et al., 2018) for similar membranes used. Once the filtering surface is known, the BW flux and flowrate can be determined. Furthermore, by this modelling approach, the number of fibres used in the process can be determined by knowing the physical characteristics of the membranes (e.g. number of channels, internal diameter and useful length), thus allowing to deduce the particle concentration of BW water. In this study, simulations are done for an industrial membrane length of $1 \mathrm{~m}$.

\section{Results and discussion}

\subsection{Ultrafiltration experiments}

\subsubsection{Dead-end}

Whatever the operating conditions and for a real CMP effluent concentration of $2600 \mathrm{mgNPs} \mathrm{L}^{-1}$ the hollow fibres are completely fouled after few seconds of filtration, which is a too short time to collect enough experimental data for filtration monitoring. Therefore, the real CMP effluent was diluted with ultrapure water. Three diluted CMP solutions at different NPs concentrations are tested $\left(97,251\right.$, and $\left.657 \mathrm{mgNPs} \mathrm{L}^{-1}\right)$, this in order to evaluate the effect of different NPs concentrations on filtration performances and hence validate and improve the UF models for a TMP of 0.4 bar.

As shown in Fig. 2, the more the effluent is concentrated, the faster the hollow fibres are fouled, and the permeate flux decreases more rapidly. According to the permeability limit set $(20 \%$ of initial permeability of filtration step), the duration of the filtration step increases from 7.5, 20 to $50 \mathrm{~min}$ when decreasing the NPs concentration from 657, 251, to $97 \mathrm{mgNPs} \mathrm{L}^{-1}$ respectively under 0.4 bar of TMP. These results are in good agreement with the findings of Hong et al. (1997), who observed faster membrane fouling at higher concentrations of silica suspensions (size $100 \mathrm{~nm}$ ). Most probably, the convective particle flux entering the cake layer increased

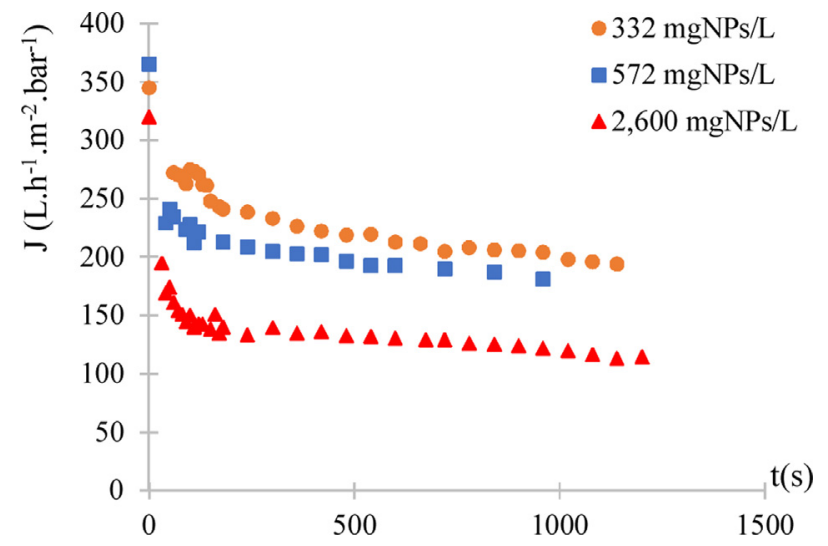

Fig. 3 - Experimental permeate flux as a function of filtration time for the different NPs concentrations [TMP $=0.3$ bar, crossflow filtration. $\mathrm{T}=20^{\circ} \mathrm{C}$ ].

with increasing NPs concentrations, thus promoting particle accumulation into the cake layer and increasing its hydraulic resistance.

\subsubsection{Crossflow}

Crossflow UF experiments are performed by using diluted real CMP wastewater at 332, 572 and 2600 mgNPs L $^{-1}$ under TMP conditions of 0.3 bar. As already found for dead-end filtrations, the permeate flux decreases faster with increasing the initial NPs concentration (Fig. 3). As shown in Figs. 2 and 3, the experimental curves of flux as a function of time for crossflow filtration mode differs from those observed for dead-end filtration mode. When carrying out crossflow filtration, permeate flux stabilized to values around 200, 230, and $150 \mathrm{~L} \mathrm{~h}^{-1} \mathrm{~m}^{-2}$ after 2-3 min for initial concentrations of 332, 572, and $2600 \mathrm{mgNPs} \mathrm{L}^{-1}$, respectively, while permeate flux still decreases until the end of the experiments during dead-end filtration. The recirculation of retentate in crossflow filtration may induce a tangential shear velocity which prevents membrane fouling, thus promoting a longer filtration step, as already observed in the literature (Koltuniewicz et al., 1995). Therefore, longer filtration steps allowed the use of higher NPs suspensions for crossflow filtration rather than those used for dead-end filtration experiments.

\subsection{Modelling experimental results}

\subsubsection{Dead-end filtration flux modelling}

When using Eq. (1) to model filtration flux, Hong et al. (1997) considered a cake porosity equal to 0.36 corresponding to a maximum stack of spheres. However, Lee and Clark (1998) have proposed an empirical equation (Eq. (5)), which is developed by UF experiments of monodisperse polystyrene latex microspheres suspension to determine the cake porosity according to NPs size. Considering the NPs size in CMP wastewater, calculation of cake porosity by the Lee and Clark equation gives the value of 0.4 . The higher the porosity, the less the modelled flux curves correlate with the experimental results, thus showing an overestimation of the permeate flux (Fig. 4B). Overestimation of the flux can involve a poor process assessment when modelling a filtration unit, as it can lead, for example, to an underestimation of the filtering surface. Therefore, in order to improve the model and hence to better describe the experimental data, coefficients of Eq. (5) are modified by performing a RMSE analysis between modelled and experimental flux values for the three initial NPs concen- 

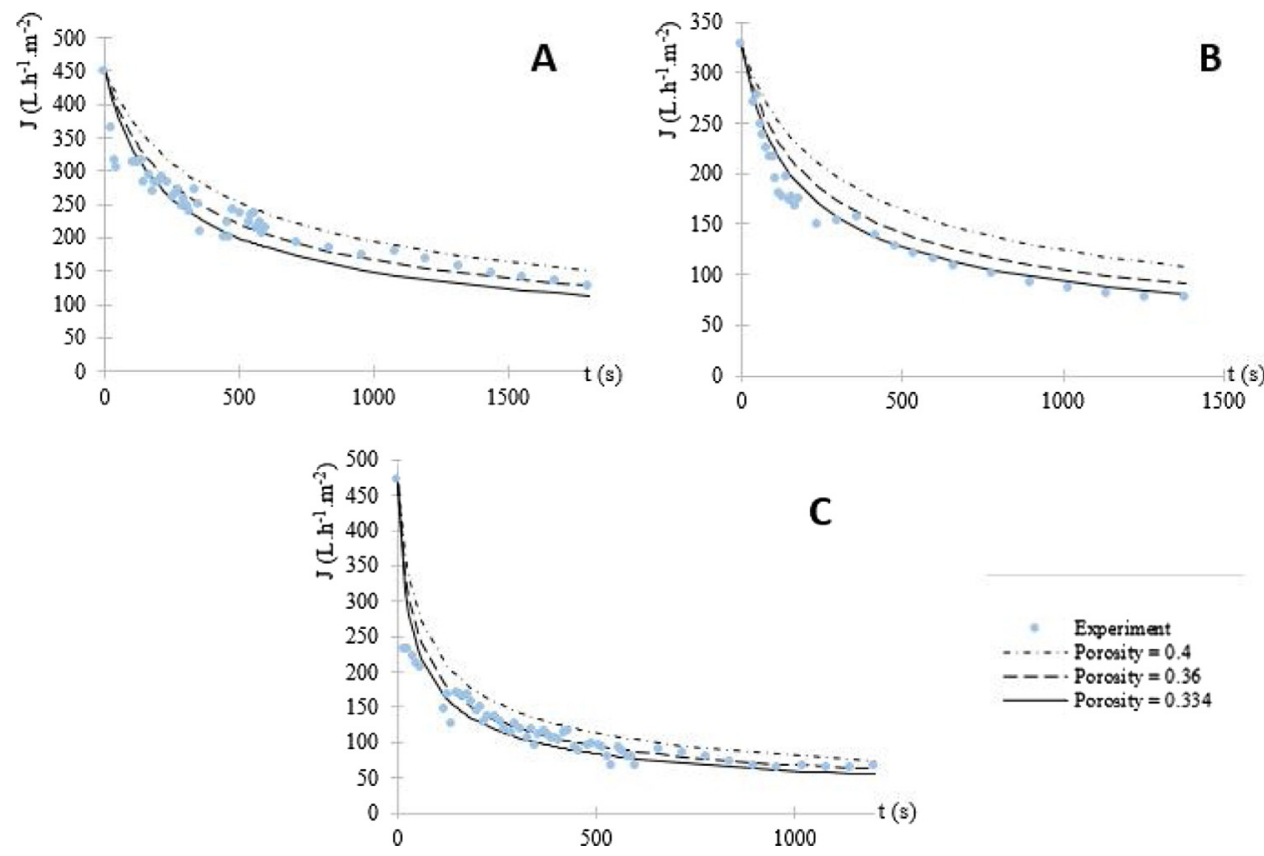

Fig. 4 - Experimental and modelled permeate fluxes as a function of filtration time (A) $97 \mathrm{mgNPs} \mathrm{L}^{-1}$; (B) $251 \mathrm{mgNPs} \mathrm{L}^{-1}$; (C) $657 \mathrm{mgNPs} \mathrm{L}^{-1}$ [TMP $=0.4 \mathrm{bar}$, dead-end filtration. $\mathrm{T}=20^{\circ} \mathrm{C}, \mu=0.001003 \mathrm{~Pa}$ s].

\begin{tabular}{lll}
$\begin{array}{l}\text { Table 1 - RMSE values between experimental and } \\
\text { modelled fluxes for different porosities. }\end{array}$ \\
\hline Porosity & NPs concentration $\left(\right.$ mgNPs L $\left.^{-1}\right)$ & RMSE \\
\hline 0.4 & 97 & 6.86 \\
& 251 & 8.46 \\
0.36 & 657 & 4.97 \\
& 97 & 4 \\
& 251 & 4.9 \\
0.334 & 657 & 3 \\
& 97 & 4.06 \\
& 251 & 2.74 \\
& 657 & 2.51 \\
\hline
\end{tabular}

trations used in this study. The final values of the coefficients are shown in Eq. (10), thus giving a cake porosity of 0.334 . The RMSE values obtained for each initial NPs concentration at the different cake porosities are presented on Table 1. Fig. 4 shows the modelled permeate fluxes of the three suspensions for the different values of cake porosity:

$n=0.089+\frac{1}{\sqrt{d_{p}}}+0.053$

Table 1 reveals that the small variation of the porosity causes a relatively strong impact on the RMSE results for a given suspension. It means that porosity is a sensitivity parameter with a significant impact on the filtration flux. As indicated by Fig. 4, the model describes the experimental results better when using a porosity of 0.334 . Overall, the results indicate that Eq. (1) can efficiently describes the experimental permeate flux decline in dead-end filtration mode when the improved porosity model of Lee and Clark (Eq. (10)) is used to determine the cake porosity. However, the modelled flux for the less concentrated suspension $\left(97 \mathrm{mgNPs} \mathrm{L}^{-1}\right.$ ) is slightly underestimated compared to the other suspensions ( 251 and $657 \mathrm{mgNPs} \mathrm{L}^{-1}$ ), as shown in Fig. 4A-C, respectively. CMP wastewater used in this study is probably not an ideal monodisperse spherical particles suspension, as it contains mostly spherical silica NPs but also silica particles whose shape could have been damaged by the abrasion during the CMP process. In addition, CMP effluents are also composed of metallic particles torn off from the microchip surfaces that may not present a spherical shape and a different size rather than those of the silica NPs. On the other hand, granulometric measurement showed that CMP effluent is polydisperse with NPs size ranging from 50.75 to $190.1 \mathrm{~nm}$. Moreover, the high dilution of the suspension which presents a low conductivity (particle interactions) can explain the least accurate fitting of the most diluted suspension.

\subsubsection{Crossflow filtration flux modelling}

The experimental fluxes of permeate (J) for the suspensions at NPs concentrations of 332,572 , and $2600 \mathrm{mgNPs} \mathrm{L}^{-1}$ were modelled according to Eq. (1), this by using the modified Lee and Clark porosity equation (Eq. (10)) to determine the cake porosity $(n=0.334)$. Fig. 5 shows the experimental and modelled flux curves for each suspension. The results indicate that modelled permeate flux is always underestimated compared to the experimental results. Indeed, as mentioned above, Eq. (1) is suitable for a dead-end filtration mode, and results of this study confirm that this model cannot be applied for UF of CMP wastewater in crossflow mode. Therefore, the empirical Eq. (11), based on the Hong et al. (1997) Eq. (1), is proposed to better describe the experimental fluxes. In Eq. (11), the tangential velocity $u\left(\mathrm{~m} \mathrm{~s}^{-1}\right)$, which is an essential parameter in crossflow filtration, is introduced as well as two parameters that are determined by RMSE analysis between experimental and modelled results. The changes made on the model concern the addition of a factor $\left(\left(a \times C_{0}\right) / u\right)$ to the time dependent part of Eq. (1), where $a$ is a parameter, and the addition of a second correction factor $b$ :

$J=J_{0}\left(\left(1+\frac{a C_{0}^{2} 3 k_{B} T A s\left(\theta_{\text {max }}\right) \mathrm{TMP}}{u \pi a_{p}^{3} D\left(\pi R_{m}\right)^{2} \rho_{\mathrm{S}}} t\right)^{-1 / 2}+b\right)$

RMSEs between modelled and experimental filtration fluxes are performed to adjust both parameters. The final configuration of Eq. (11) presented in this study is selected based 
Table 2 - RMSE analysis between experimental and modelled fluxes by using Eqs. (1) and (11).

\begin{tabular}{lll}
$n=0.334$ & Concentration $\left(\mathrm{mgNPs} \mathrm{L}^{-1}\right)$ & RMSE \\
\hline Eq. (1) & 332 & 18.5 \\
& 572 & 21.8 \\
Eq. (11) & 2600 & 13.63 \\
& 332 & 2.3 \\
& 572 & 4.58 \\
& 2600 & 1.78
\end{tabular}

on the lowest average weighted RMSEs calculated considering the three suspensions studied for the cake porosity of 0.334 with a correction factor $a=0.5 \mathrm{~m}^{4} \mathrm{~s}^{-1} \mathrm{~kg}^{-1}$ and $b=0.35$. Table 2 summarizes the results of RMSE analyses between experimental and modelled fluxes by using Eqs. (1) and (11).

As shown in Fig. 5 and in Table 2, empirical equation (11) describes efficiently the evolution of permeate flux in the range of the concentration used.

As emphasized, Hong et al. equation is not suitable to model NPs filtration performed for this study. It must be re that Hong et al. validated in their study, the initial model (Eq. (1)) on very dilute solutions and this could explain such differences.

\section{Ultrafiltration process simulation}

\subsection{Dead-end model simulation}

The developed model is tested in simulated industrial conditions for the three different CMP suspensions used in dead-end experiments $\left(97,251\right.$ and $\left.657 \mathrm{mgNPs} \mathrm{L}^{-1}\right)$. An average permeate flowrate of $100 \mathrm{~m}^{3} \mathrm{~h}^{-1}$, which represents a typical value observed for CMP wastewater flowrate, $1 \mathrm{~min}$ of $\mathrm{BW}$, and $3 \mathrm{~h}$ of $\mathrm{CW}$ are considered. All simulations are done at $20^{\circ} \mathrm{C}$. The design and the performance of the process are estimated by considering filtration times of 20 and $60 \mathrm{~min}$. Table 3 summarizes the main results from simulations performed by considering different filtration times, different NP concentrations, and different TMPs.
The results indicate that it is impossible to simulate the filtration step for high concentration and/or high filtration duration due to high fouling, as the time to reach the limit of permeability ( $20 \%$ of the initial permeability) engaging a $\mathrm{CW}$ is lower than the filtration duration (i.e. filtration number $=1$ ). For example, the number of filtrations, corresponding to the number of cycles +1 , indicates that for $60 \mathrm{~min}$ of filtration, only two operating conditions are viable. Indeed, for the suspension of $97 \mathrm{mgNPs} \mathrm{L}^{-1}$, only pressures of 0.2 and $0.3 \mathrm{bar}$ allowed to ensure suitable process operations since under 0.4 bar the final permeability limit of $20 \%$ is reached after a single filtration and the $\mathrm{CW}$ must be performed. For this reason, the process parameters are not determined in these conditions. Instead, for the lowest filtration duration $(20 \mathrm{~min})$, all the conditions tested for the concentration of $97 \mathrm{mgNPs} \mathrm{L}^{-1}$ are viable as well as the two lowest pressure for the concentration of $251 \mathrm{mgNPs} \mathrm{L}^{-1}$. Moreover, simulation of dead-end filtration mode indicated that only one suspension $\left(97 \mathrm{mgNPs} \mathrm{L}^{-1}\right)$ presents noticed characteristics about the filtration duration for TMP between 0.2 to $0.4 \mathrm{bar}$, and this respecting filtration times mentioned in the literature (20-60 min) (Cordier et al., 2018; Payant, 2016). Overall, results of this study clearly indicate that dead-end filtration is not suitable for CMP effluents whose concentration exceeds $100 \mathrm{mgNPs} \mathrm{L}^{-1}$. However, real CMP effluents usually have a very higher NP concentration ( $2600 \mathrm{mgNPs} \mathrm{L}^{-1}$ ) compared to the diluted effluents tested in this study. Therefore, this filtration mode is not suitable for the treatment of real undiluted CMP effluents and crossflow filtration mode is therefore considered.

\subsection{Crossflow model simulation}

The developed model is tested in simulated industrial conditions for the three different CMP suspensions used in crossflow experiments $\left(332,572\right.$ and 2600 mgNPs L $\left.^{-1}\right)$. The values of $1 \mathrm{~min}$ of $\mathrm{BW}$ and $3 \mathrm{~h}$ of $\mathrm{CW}$ are considered. All simulations are done at $20^{\circ} \mathrm{C}$ and according to a tangential velocity of $0.5 \mathrm{~m} \mathrm{~s}^{-1}$. Figs. 6 and 7 present the simulated results for the three diluted suspensions used in this study. For each

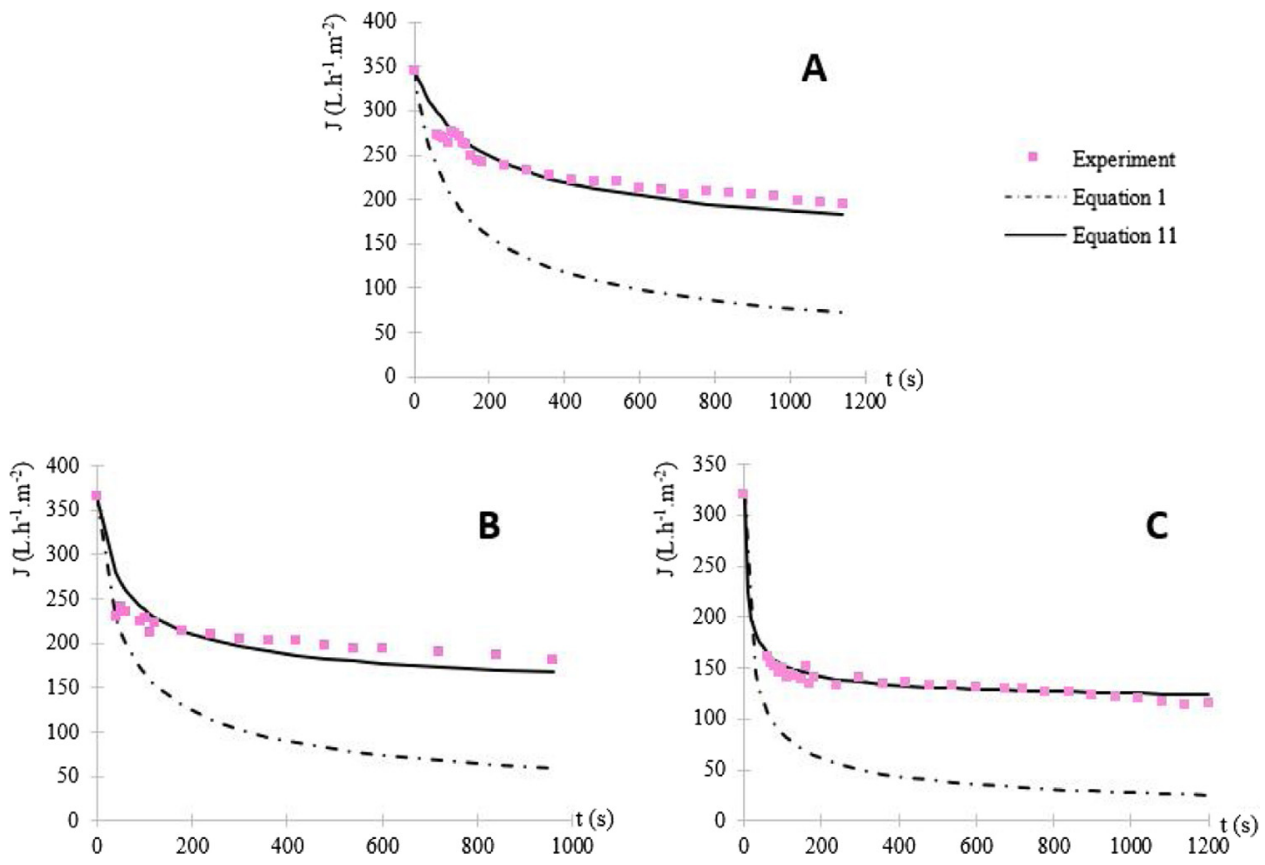

Fig. 5 - Experimental and modelled permeate fluxes as a function of filtration time (A) $332 \mathrm{mgNPs} \mathrm{L}^{-1}$; (B) $571 \mathrm{mgNPs} \mathrm{L}^{-1}$; (C) $2600 \mathrm{mgNPs} \mathrm{L}^{-1}$ [TMP $=0.3 \mathrm{bar}$, crossflow filtration. $\mathrm{T}=20^{\circ} \mathrm{C}, \mu=0.001003 \mathrm{~Pa}$ s]. 
Table 3 - Simulated dead-end ultrafiltration process for different filtration times, NPs concentrations, and TMP.

\begin{tabular}{|c|c|c|c|c|c|c|c|}
\hline Filtration duration (min) & $\begin{array}{l}\text { Initial } \\
\text { concentration } \\
\left(\text { mgNPs L }^{-1}\right)\end{array}$ & TMP (bar) & $\begin{array}{l}\text { Number of } \\
\text { cycles }\end{array}$ & $\begin{array}{l}\text { Number of } \\
\text { filtrations }\end{array}$ & $\begin{array}{l}\text { Filtering } \\
\text { surface }\left(\mathrm{m}^{2}\right)\end{array}$ & $\begin{array}{l}\text { Average } \\
\text { filtration flux } \\
\left(\mathrm{L} \mathrm{h}^{-1} \mathrm{~m}^{-2}\right)\end{array}$ & $\begin{array}{l}\text { Process } \\
\text { duration (h) }\end{array}$ \\
\hline \multirow[t]{4}{*}{60} & \multirow[t]{3}{*}{97} & 0.2 & 40 & 41 & 1508 & 72.3 & 44.7 \\
\hline & & 0.3 & 22 & 23 & 1084 & 106 & 26.4 \\
\hline & & 0.4 & I & 1 & I & I & I \\
\hline & 251 and 657 & 0.20 .30 .4 & I & 1 & I & I & I \\
\hline \multirow[t]{7}{*}{20} & \multirow[t]{3}{*}{97} & 0.2 & 50 & 51 & 1429 & 86 & 20.8 \\
\hline & & 0.3 & 48 & 49 & 1019 & 121 & 20 \\
\hline & & 0.4 & 46 & 47 & 808 & 154 & 19.4 \\
\hline & \multirow[t]{3}{*}{251} & 0.2 & 42 & 43 & 1695 & 74.3 & 18 \\
\hline & & 0.3 & 32 & 33 & 1253 & 105.6 & 14.5 \\
\hline & & 0.4 & I & 1 & l & I & I \\
\hline & 657 & 0.20 .30 .4 & I & 1 & I & l & I \\
\hline
\end{tabular}
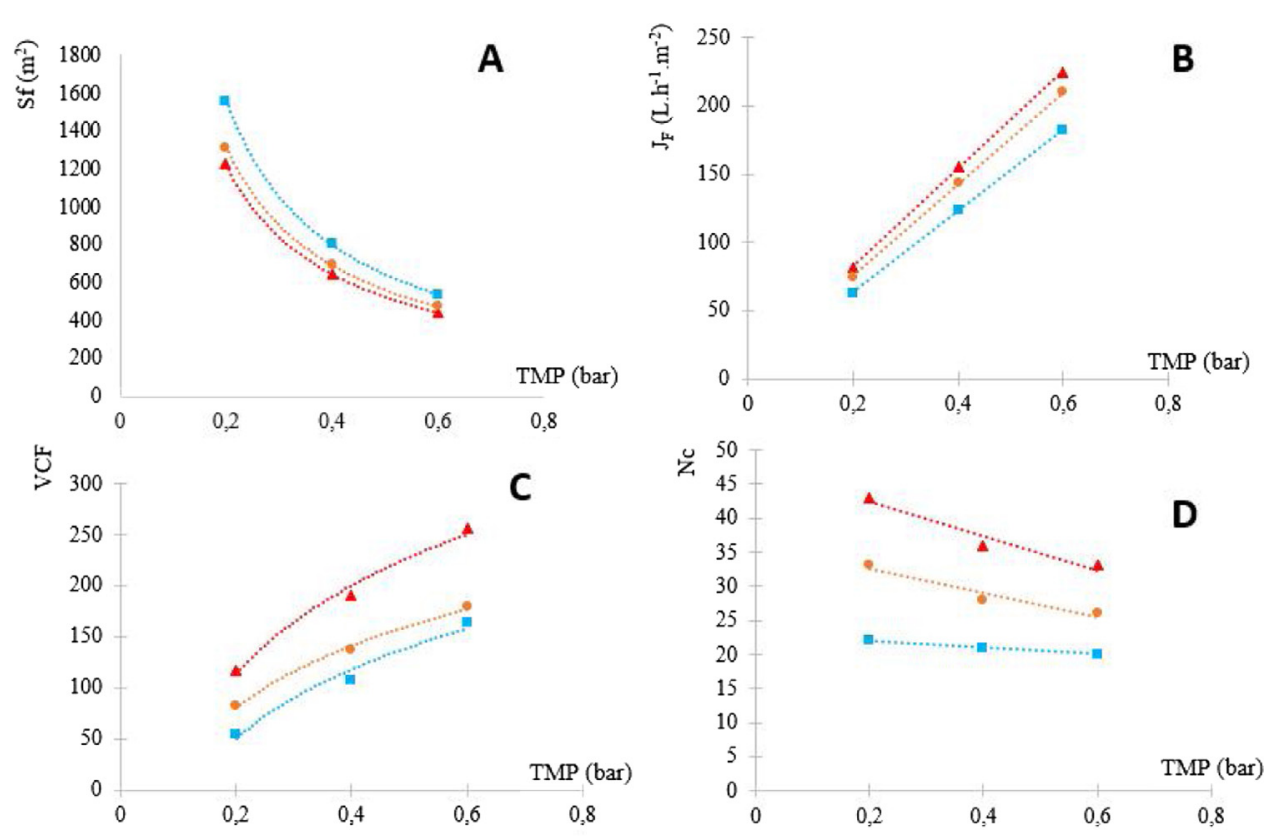

$\triangle 332 \mathrm{mgNPs} / \mathrm{L}$
$-572 \mathrm{mgNPs} / \mathrm{L}$

Fig. 6 - Theoretical crossflow UF process parameters as a function of TMP for the different NPs concentrations: (A) filtering surface; (B) average filtration flux; (C) average VCF; (D) number of cycles [filtration duration $=60 \mathrm{~min}$ ].

suspension and for a fixed filtration duration (Fig. 6A), the needed filtering surface decreases with increasing TMP from 0.2 to 0.6 bar. On the contrary, the average filtration flux $\left(U_{F}\right)$ and the average VCF increase with increasing TMP (Fig. 6B and C). Indeed, the higher the TMP, the greater the average filtration flux. As shown in Fig. 6D, the number of cycles slightly decreases with increasing TMP, and this is likely related to the growing fouling. As already discussed in Section 3.1, the tangential velocity applied in crossflow ultrafiltration process limits the fouling rate. For this reason, the cake layer for the crossflow is less thick than for the dead-end mode, and the permeate flux appears more important and it can stabilize: a strongly decrease of the membrane surface is observed (Fig. 6A) (vs. dead end filtration). As shown in Fig. 5, the permeate fluxes are quickly stabilized and their declines are very slow. For each suspension, the limit of $20 \%$ of the initial permeability before CW is reached at the end of several filtration/backwashing cycles (Fig. 6D), where the number of cycles is evaluated for each concentration under different TMPs. In this case, the main parameter considered is the needed filtering surface depending on the filtration duration which controls the VCF and operating parameters.

At a fixed value of TMP ( $0.3 \mathrm{bar})$, increasing the filtration duration induces a slight decrease of filtration flux and then a little larger needed filtering surface (Fig. 7B and A). For example, for a filtration of $332 \mathrm{mgNPs} \mathrm{L}^{-1}$ under 0.3 bar of TMP, the filtering surfaces needed for 20 and $60 \mathrm{~min}$ of filtration correspond to 763 and $842 \mathrm{~m}^{2}$, respectively, with filtration flux of 128.6 and $118.3 \mathrm{~L} \mathrm{~h}^{-1} \mathrm{~m}^{-2}$. On the contrary, the increasing of filtration duration generates significant higher VCF (Fig. 7D). Overall, Figs. 6 and 7 show that greater variations of parameters $\left(S f, J_{F}, V C F\right.$ and $N c$ ) are observed when the TMP changes from 0.2 to 0.6 bar than when TMP is fixed and the filtration duration increases from 20 to $60 \mathrm{~min}$. Ye et al. (2010) investigated the filtration duration effect on membrane fouling and they observed that the membrane permeability recovery did not increase when filtration duration increased from 20 to 60 min but, when filtration duration further increased from 60 to $90 \mathrm{~min}$, a more compact cake layer appeared. They supposed that irreversible fouling appears in the first few cycles. There- 

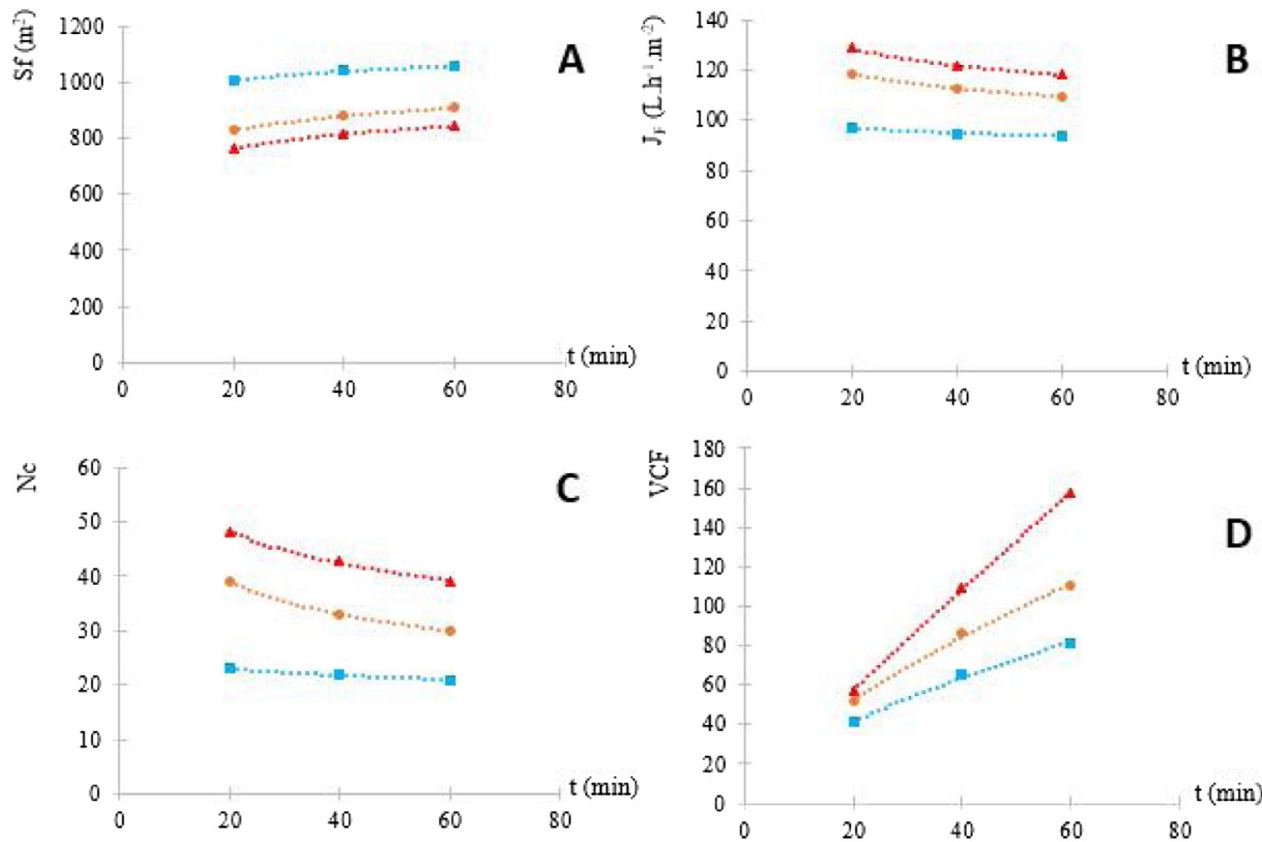

4 $332 \mathrm{mgNPs} / \mathrm{L}$
$=572 \mathrm{mgNPs} / \mathrm{L}$
$=2,600 \mathrm{mgNP} / \mathrm{L}$

Fig. 7 - Theoretical crossflow UF process parameters as a function of filtration duration for the different NPs concentrations: (A) filtering surface; (B) average filtration flux; (C) number of cycles; (D) average VCF [TMP = 0.3 bar].

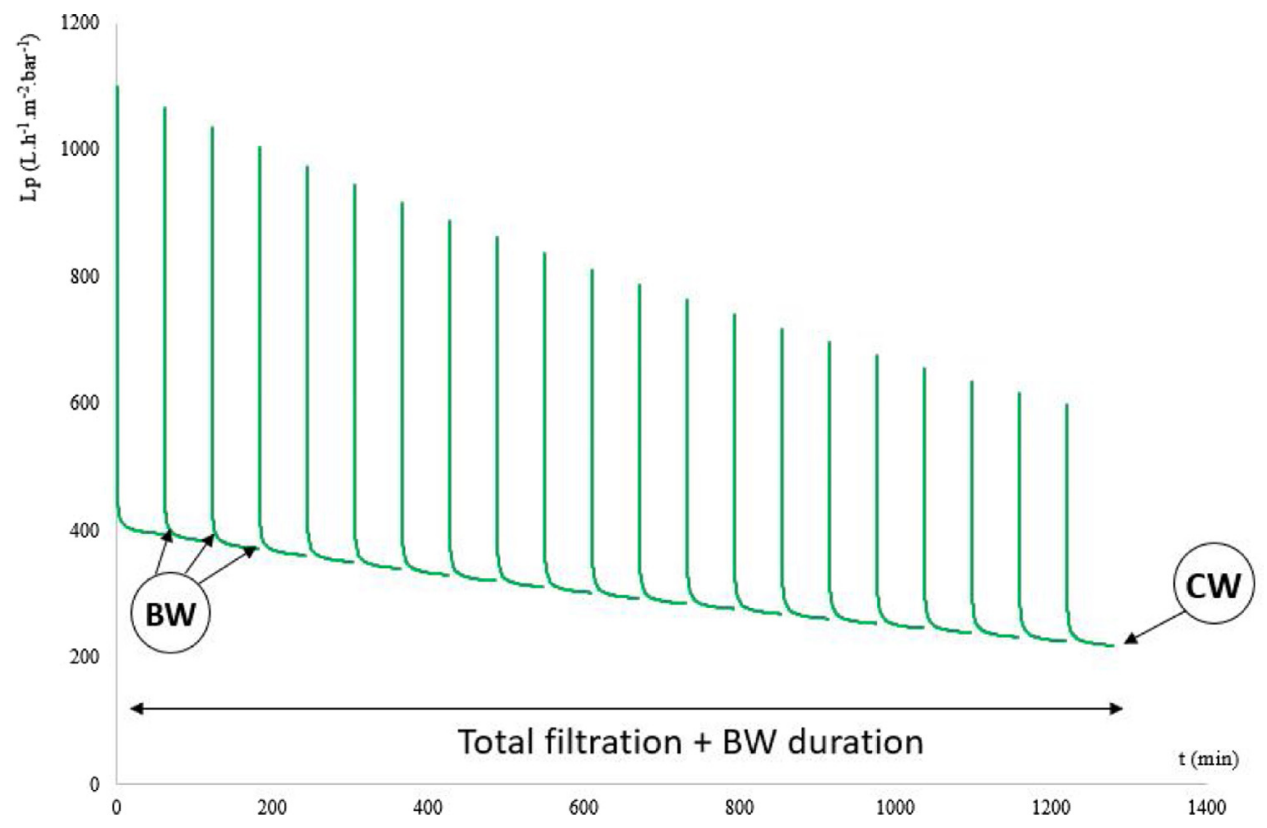

Fig. 8 - Modelled variation of filtration fluxes in function of process duration [TMP $=0.6 \mathrm{bar}$, filtration duration $=60 \mathrm{~min}$, $\left.\mathrm{C}_{0}=2600 \mathrm{mgNPs} \mathrm{L}^{-1}\right]$.

fore, it is possible to extend the filtration duration without change of membrane permeability recovery. However, in this case, the filtration flux will decrease, and the filtering surface needed would become more important. On the other hand, the number of cycles decreases with increasing the filtration duration as results of the growing fouling.

Generally, for all simulations, the smallest filtering surfaces and the highest filtration fluxes are obtained for the highest TMP or for the shortest filtration duration. According to these results, the better treatment for highly concentrate CMP wastewaters (2600 $\mathrm{mgNPs} \mathrm{L}^{-1}$ ) seems to be the crossflow ultrafiltration allowing to get a long filtration duration, this to keep the membrane integrity longer before CW and to consider the lowest filtering surface. Considering the real CMP effluent concentration ( $2600 \mathrm{mgNPs} \mathrm{L}^{-1}$ ) for a filtration duration of $60 \mathrm{~min}$ and a TMP of $0.6 \mathrm{bar}$, it is possible to simulate the filtration/washing step between two CWS (Fig. 8). In these conditions, the total duration process including $\mathrm{CW}(3 \mathrm{~h})$ amounts to $24 \mathrm{~h}$ and the average and final filtration flux are respectively 185 and $137 \mathrm{~L} \mathrm{~h}^{-1} \mathrm{~m}^{-2}$.

The complete model also allows to involve the influence of the tangential velocity on the filtration flux and the VCF. Fig. 9 represents the evolution of the permeate fluxes vs $\ln (\mathrm{VCF})$ for high concentrate CMP effluent $\left(2600 \mathrm{mgNPs} \mathrm{L}^{-1}\right)$ at var- 


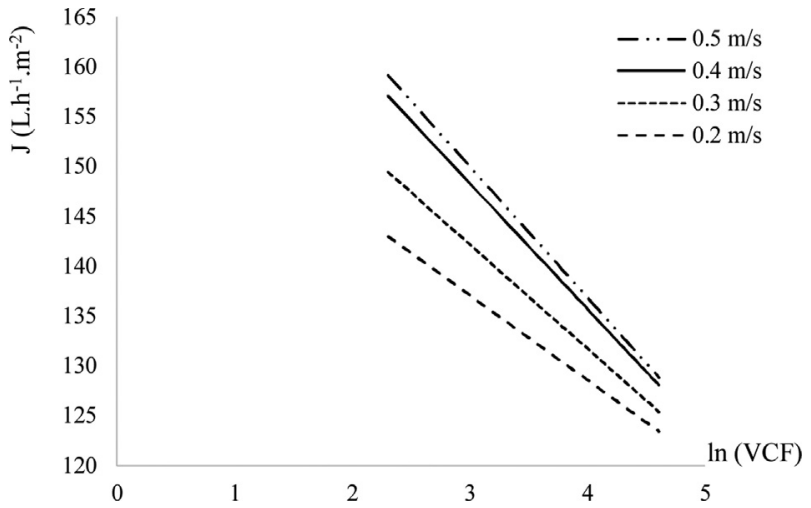

Fig. 9 - Modelled evolution of permeate flux with $\ln$ (VCF) for $2600 \mathrm{mgNPs} \mathrm{L}^{-1}$ of CMP effluent at various tangential velocity under 0.3 bar of TMP and $20^{\circ} \mathrm{C}$.

ious tangential velocities $\left(0.2,0.3,0.4\right.$ and $\left.0.5 \mathrm{~m} \mathrm{~s}^{-1}\right)$ under 0.3 bar of TMP and $20^{\circ} \mathrm{C}$, this considering an initial membrane permeability of $1100 \mathrm{~L} \mathrm{~h}^{-1} \mathrm{~m}^{-2} \mathrm{bar}^{-1:} \mathrm{Eq}$. (7) is determined for each velocity value according to the modelling approach presented in Section 2.2. Results represent the maximum flux values that can be obtained depending on the referred concentration (represented by the VCF). As expected, the higher the tangential velocity and the lower the concentration (VCF), the higher the maximum flux. This method can be applied on various parameters including TMP, effluent concentrations, membrane permeability and temperature.

\section{Conclusion}

This study shows that the model proposed by Hong et al. (1997) efficiently describes the permeate flux decline for deadend UF of nanoparticle suspensions under constant TMP. The optimization of the Lee and Clark (1998) equation allows to determine a cake porosity of 0.334 that is valid for both the dead-end and the crossflow UF of the CMP wastewaters. A new correlation is proposed for real CMP effluent to predict the trend of crossflow UF fluxes under constant TMP. There is a good agreement between the modelled and experimental fluxes for the two filtration modes even if a slight underestimation for the most highly diluted suspensions is observed $\left(<100 \mathrm{mgNPs} \mathrm{L}^{-1}\right)$. Complete UF robust hybrid models are proposed to evaluate the performances of UF for the treatment of CMP effluents. The models developed allow to predict the filtration number of cycles and are easily adjustable according to the permeability recovery rate after physical washes of the membrane, the duration of washes (physical and chemical) and many operating parameters such as the TMP, the NPs concentration, the temperature, and the tangential velocity (for crossflow mode). Moreover, models can predict the VCF in function of filtration duration, and they can design UF process with finding the filtering surface needed depending on operating conditions. Simulated results show that dead-end filtration mode is suitable for NPs suspension smaller than $100 \mathrm{mgNPs} \mathrm{L}^{-1}$. It appears that the most suitable treatment for concentrated CMP effluents is the crossflow ultrafiltration process, which is more adapted for filtration of highly concentrated suspensions and provided longer filtration times. Results of crossflow UF model show that greater variations of parameters (Sf, $J_{F}, V C F$ and $N c$ ) are observed when the TMP changes rather than when TMP is fixed and the filtration duration increases, this in the ranges of values that was studied.
To our knowledge, this is the first comprehensive study on the dynamic simulation of constant TMP ultrafiltration process suitable for the treatment of CMP effluents. The data provided by the developed models and the present study may be necessary for semiconductor and microelectronic industries. It would allow them to predict and to adjust the operating conditions of the ultrafiltration process according to their needs. The crossflow hybrid model proposed in this study could allow microelectronic manufacturers to design UF process configuration.

\section{Conflict of interest}

None declared.

\section{Acknowledment}

The authors thanks the French Ministery of Research for the PhD grant support.

\section{References}

Akhondi, E., Wicaksana, F., Fane, A.G., 2014. Evaluation of fouling deposition, fouling reversibility and energy consumption of submerged hollow fiber membrane systems with periodic backwash. J. Membr. Sci. 452, 319-331, http://dx.doi.org/10.1016/j.memsci.2013.10.031.

Arénillas, S., Drouin, M., Monnin, E., Moulin, P., 2017. Glycerin removal from ultrafiltration flat sheet membranes by filtration and soaking. J. Membr. Sci. Res. 3, 102-108.

Bacchin, P., Si-Hassen, D., Starov, V., Clifton, M.J., Aimar, P., 2002. A unifying model for concentration polarization, gel-layer formation and particle deposition in cross-flow membrane filtration of colloidal suspensions. Chem. Eng. Sci. 57, 77-91, http://dx.doi.org/10.1016/S0009-2509(01)00316-5.

Baudry, I., 2014. Caractérisation des process de fabrication microélectroniques pour l'éco-conception des futures technologies (Ph.D. thesis). University of Grenoble, France.

Berland, J.-M., Juery, C., 2002. Les procédés membranaires pour le traitement de l'eau (FNDAE No. 14). France.

Bernard, P., 2006. Étude du polissage mécano-chimique du cuivre et modélisation du processus d'enlèvement de matière (Ph.D. thesis). Ecole Centrale de Lyon, France.

Chen, V., Fane, A.G., Madaeni, S., Wenten, I.G., 1997. Particle deposition during membrane filtration of colloids: transition between concentration polarization and cake formation. J. Membr. Sci. 125, 109-122, http://dx.doi.org/10.1016/S0376-7388(96)00187-1.

Cheng, T.-W., Yeh, H.-M., 2008. Complete momentum-balance analysis of permeate flux for ultrafiltration in hollow-fiber modules. Tamkang J. Sci. Eng. 11, 239-246.

Chin, C.-J.M., Chen, P.-W., Wang, L.-J., 2006. Removal of nanoparticles from CMP wastewater by magnetic seeding aggregation. Chemosphere 63, 1809-1813, http://dx.doi.org/10.1016/j.chemosphere.2005.09.035.

Choi, H., Zhang, K., Dionysiou, D.D., Oerther, D.B., Sorial, G.A., 2005. Effect of permeate flux and tangential flow on membrane fouling for wastewater treatment. Sep. Purif. Technol. 45, 68-78, http://dx.doi.org/10.1016/j.seppur.2005.02.010.

Chou, W.-L., Wang, C.-T., Chang, S.-Y., 2009. Study of COD and turbidity removal from real oxide-CMP wastewater by iron electrocoagulation and the evaluation of specific energy consumption. J. Hazard. Mater. 168, 1200-1207, http://dx.doi.org/10.1016/j.jhazmat.2009.02.163.

Cordier, C., Stavrakakis, C., Sauvade, P., Coelho, F., Moulin, P., 2018. Air backwash efficiency on organic fouling of UF membranes applied to shellifish hatchery effluents. Membranes 8, 48, http://dx.doi.org/10.3390/membranes8030048. 
de Luna, M.D.G., Warmadewanthi, Liu, J.C., 2009. Combined treatment of polishing wastewater and fluoride-containing wastewater from a semiconductor manufacturer. Colloids Surf. A: Physicochem. Eng. Aspects 347, 64-68, http://dx.doi.org/10.1016/j.colsurfa.2008.12.006, Interfaces Against Pollution5th International Conference on Interfaces Against Pollution 2008, Kyoto, Japan, 1-4 June 2008.

Diagne, N.W., 2014. Le nettoyage: une étape-clef pour une production durable par procédé à membrane: réflexion sur le lien entre conditions de production et nettoyabilité d'une membrane PES de l'industrie laitière (Ph.D. thesis). University of Rennes, France.

Elimelech, M., Bhattacharjee, S., 1998. A novel approach for modeling concentration polarization in crossflow membrane filtration based on the equivalence of osmotic pressure model and filtration theory. J. Membr. Sci. 145, 223-241, http://dx.doi.org/10.1016/S0376-7388(98)00078-7.

Guadix, A., Sørensen, E., Papageorgiou, L.G., Guadix, E.M., 2004. Optimal design and operation of continuous ultrafiltration plants. J. Membr. Sci. 235, 131-138, http://dx.doi.org/10.1016/j.memsci.2004.02.003.

Happel, J., 1958. Viscous flow in multiparticle systems: slow motion of fluids relative to beds of spherical particles. AIChE J. 4, 197-201, http://dx.doi.org/10.1002/aic.690040214.

Happel, J., Brenner, H., 1965. Low Reynolds Number Hydrodynamics, With Special Applications to Particulate Media.

Hong, S., Faibish, R.S., Elimelech, M., 1997. Kinetics of permeate flux decline in crossflow membrane filtration of colloidal suspensions. J. Colloid Interface Sci. 196, 267-277, http://dx.doi.org/10.1006/jcis.1997.5209.

Huang, C.J., Yang, B.M., Chen, K.S., Chang, C.C., Kao, C.M., 2011. Application of membrane technology on semiconductor wastewater reclamation: a pilot-scale study. Desalination 278, 203-210, http://dx.doi.org/10.1016/j.desal.2011.05.032.

Ji, D.-R., Chang, C.-C., Wu, Y.-L., Chang, C.-Y., Tu, W.-K., Tseng, J.-Y., Wang, T.-T., Chang, C.-F., Chiu, C.-Y., Chen, Y.-H., 2010. Treatment of methyl methacrylate from semiconductor wastewater by catalytic wet oxidation. J. Taiwan Inst. Chem. Engrs. 41, 209-215, http://dx.doi.org/10.1016/j.jtice.2009.06.003.

Kim, S., Marion, M., Jeong, B.-H., Hoek, E.M.V., 2006. Crossflow membrane filtration of interacting nanoparticle suspensions. J. Membr. Sci. 284, 361-372, http://dx.doi.org/10.1016/j.memsci.2006.08.008.

Koltuniewicz, A.B., Field, R.W., Arnot, T.C., 1995. Cross-flow and dead-end microfiltration of oily-water emulsion. Part I: experimental study and analysis of flux decline. J. Membr. Sci. 102, 193-207, http://dx.doi.org/10.1016/0376-7388(94)00320-X.

Le Hir, M., Wyart, Y., Georges, G., Siozade, L., Moulin, P., 2018. Nanoparticles retention potential of multichannel hollow fiber drinking water production membrane. J. Membr. Sci. Res. $4,74-84$

Lee, Y., Clark, M.M., 1998. Modeling of flux decline during crossflow ultrafiltration of colloidal suspensions. J. Membr. Sci. 149, 181-202, http://dx.doi.org/10.1016/S0376-7388(98)00177-X.

Liu, Y.-H., Lin, C.-Y., Huang, J.-H., Yen, S.-C., 2016. Particle removal performance and its kinetic behavior during oxide-CMP wastewater treatment by electrocoagulation. J. Taiwan Inst. Chem. Engrs. 60, 520-524, http://dx.doi.org/10.1016/j.jtice.2015.11.023.

Lo, R., Lo, S.L., 2004. A pilot plant study using ceramic membrane microfiltration, carbon adsorption and reverse osmosis to treat CMP (chemical mechanical polishing) wastewater. Water Sci. Technol. 4, 111-118.

Marriott, J.I., Sørensen, E., Bogle, I.D.L., 2001. Detailed mathematical modelling of membrane modules. Comput. Chem. Eng., 8.

Ndiaye, P.I., Moulin, P., Dominguez, L., Millet, J.C., Charbit, F., 2004. Treatment of silica effluents: ultrafiltration or coagulation-decantation. J. Hazard. Mater. 116, 75-81, http://dx.doi.org/10.1016/j.jhazmat.2004.07.006.
Pansare, V.J., Tien, D., Thoniyot, P., Prud'homme, R.K., 2017. Ultrafiltration of nanoparticle colloids. J. Membr. Sci. 538, 41-49, http://dx.doi.org/10.1016/j.memsci.2017.03.041.

Pascual, X., Gu, H., Bartman, A.R., Zhu, A., Rahardianto, A., Giralt, J., Rallo, R., Christofides, P.D., Cohen, Y., 2013. Data-driven models of steady state and transient operations of spiral-wound RO plant. Desalination 316, 154-161, http://dx.doi.org/10.1016/j.desal.2013.02.006.

Payant, A., 2016. Efficacité des lavages physiques de membranes de nanofiltration à fibres creuses.

Remize, P.J., Guigui, C., Cabassud, C., 2010. Evaluation of Backwash Efficiency, Definition of Remaining Fouling and Characterisation of Its Contribution in Irreversible Fouling: Case of Drinking Water Production By Air-Assisted Ultra-Filtration., pp. 104-111.

Ryu, H.-D., Kim, D., Lee, S.-I., 2008. Application of struvite precipitation in treating ammonium nitrogen from semiconductor wastewater. J. Hazard. Mater. 156, 163-169, http://dx.doi.org/10.1016/j.jhazmat.2007.12.010.

Saltık, M.B., Özkan, L., Jacobs, M., van der Padt, A., 2017. Dynamic modeling of ultrafiltration membranes for whey separation processes. Comput. Chem. Eng. 99, 280-295, http://dx.doi.org/10.1016/j.compchemeng.2017.01.035.

Sanders, N., Hubble, J., 1991. Concentration polarisation in a constant flux ultrafiltration rig: prediction of bulk protein concentrations using a lumped parameter model. J. Membr. Sci. 59, 277-292, http://dx.doi.org/10.1016/S0376-7388(00)80817-0.

Sioutopoulos, D.C., Karabelas, A.J., 2012. Correlation of organic fouling resistances in $\mathrm{RO}$ and UF membrane filtration under constant flux and constant pressure. J. Membr. Sci. 407, 34-46, http://dx.doi.org/10.1016/j.memsci.2012.03.036.

Springer, F., Laborie, S., Guigui, C., 2013. Removal of SiO2 nanoparticles from industry wastewaters and subsurface waters by ultrafiltration: investigation of process efficiency, deposit properties and fouling mechanism. Sep. Purif. Technol. 108, 6-14, http://dx.doi.org/10.1016/j.seppur.2013.01.043.

Srijaroonrat, P., Julien, E., Aurelle, Y., 1999. Unstable secondary oil/water emulsion treatment using ultrafiltration: fouling control by backflushing. J. Membr. Sci. 159, 11-20, http://dx.doi.org/10.1016/S0376-7388(99)00044-7.

Testa, F., Coetsier, C., Carretier, E., Ennahali, M., Laborie, B., Moulin, P., 2014. Recycling a slurry for reuse in chemical mechanical planarization of tungsten wafer: Effect of chemical adjustments and comparison between static and dynamic experiments. Microelectron. Eng. 113, 114-122, http://dx.doi.org/10.1016/j.mee.2013.07.022.

Testa, F., Coetsier, C., Carretier, E., Ennahali, M., Laborie, B., Serafino, C., Bulgarelli, F., Moulin, P., 2011. Retreatment of silicon slurry by membrane processes. J. Hazard. Mater. 192, 440-450, http://dx.doi.org/10.1016/j.jhazmat.2011.05.016.

Trzaskus, K.W., Lee, S.L., de Vos, W.M., Kemperman, A., Nijmeijer, K., 2017. Fouling behavior of silica nanoparticle-surfactant mixtures during constant flux dead-end ultrafiltration. J. Colloid Interface Sci. 506, 308-318, http://dx.doi.org/10.1016/j.jcis.2017.07.043.

Tsai, J.-C., Kumar, M., Chen, S.-Y., Lin, J.-G., 2007. Nano-bubble flotation technology with coagulation process for the cost-effective treatment of chemical mechanical polishing wastewater. Sep. Purif. Technol. Appl. Nanotechnol. Sep. Purif. 58, 61-67, http://dx.doi.org/10.1016/j.seppur.2007.07.022.

Van der Sman, R.G.M., Vollebregt, H.M., 2013. Transient critical flux due to coupling of fouling mechanisms during crossflow microfiltration of beer. J. Membr. Sci. 435, 21-37, http://dx.doi.org/10.1016/j.memsci.2013.01.015.

Vera, L., González, E., Ruigómez, I., Gómez, J., Delgado, S., 2015. Analysis of backwashing efficiency in dead-end hollow-fibre ultrafiltration of anaerobic suspensions. Environ. Sci. Pollut. Res. 22, 16600-16609, http://dx.doi.org/10.1007/s11356-015-4857-0. 
Waite, T.D., Schäfer, A.I., Fane, A.G., Heuer, A., 1999. Colloidal fouling of ultrafiltration membranes: impact of aggregate structure and size. J. Colloid Interface Sci. 212, 264-274, http://dx.doi.org/10.1006/jcis.1998.6040.

Ye, Y., Chen, V., Le-Clech, P., 2011. Evolution of fouling deposition and removal on hollow fibre membrane during filtration with periodical backwash. Desalination 283, 198-205,

http://dx.doi.org/10.1016/j.desal.2011.03.087, Special issue in honour of Professor Tony Fane on his 70th Birthday.

Ye, Y., Sim, L.N., Herulah, B., Chen, V., Fane, A.G., 2010. Effects of operating conditions on submerged hollow fibre membrane systems used as pre-treatment for seawater reverse osmosis. J. Membr. Sci. 365, 78-88,

http://dx.doi.org/10.1016/j.memsci.2010.08.038.
Yee, K.W.K., Alexiadis, A., Bao, J., Wiley, D.E., 2009. Effects of recycle ratios on process dynamics and operability of a whey ultrafiltration stage. Desalination 236, 216-223, http://dx.doi.org/10.1016/j.desal.2007.10.070.

Yee, K.W.K., Alexiadis, A., Bao, J., Wiley, D.E., 2008. Effects of multiple-stage membrane process designs on the achievable performance of automatic control. J. Membr. Sci. 320, 280-291, http://dx.doi.org/10.1016/j.memsci.2008.04.010.

Yorgun, M.S., Balcioglu, I.A., Saygin, O., 2008. Performance comparison of ultrafiltration, nanofiltration and reverse osmosis on whey treatment. Desalination 229, 204-216, http://dx.doi.org/10.1016/j.desal.2007.09.008. 